AGRIEKONOMIKA

http://journal.trunojoyo.ac.id/agriekonomika

Volume 9, Nomor 2, 2020

https://doi.org/10.21107/agriekonomika.v9i2.6824
Agriekonomika has been accredited as a scientific journal by the Ministry of Research-Technology and Higher Education Republic of Indonesia: No. 23/E/KPT/2019

\title{
The Application of Good Agricultural Practices of White Pepper and Factors Affecting Farmer Participation
}

\author{
${ }^{凶}$ Rostiar Sitorus, Harianto, Suharno, Yusman Syaukat \\ Agricultural Economics, Faculty of Economics and Management \\ IPB University, Indonesia \\ Received: February 2020; Accepted: October 2020; Published: October 2020
}

\begin{abstract}
The productivity of white pepper plants and the low quality of yields are the main problems that should be corrected in the management of smallholder plantations in the Bangka Belitung Islands Province. This study aims to determine the factors affecting farmer participation in implementing GAP, as well as how the GAP was implemented. The study was conducted in 3 districts namely West Bangka, Central Bangka, and South Bangka as a center of white pepper production. The respondents consisting of 142 farmers who applied GAP and 82 non-GAP farmers. By using the logit model, it is found that older farmers, more educated, have more family members, have larger planting areas and farmers who are more active in participating in GAP socialization will have more chances of deciding to implement GAP. The implementation of white pepper GAP for each component, on average ranged from 67 to 95 percent.
\end{abstract}

Keywords: Logit, Productivity, Participation, Bangka Belitung Island Province

\section{INTRODUCTION}

Increasing production and productivity of sustainable plantations is one of the activities in the 2015-2019 Directorate General Plantation Strategic Program, which is aimed at high-value and competitive plantation commodities. This is in line with the increasing demands of the international market on agricultural products in terms of product safety, product quality and environmentally friendly cultivation practices (Srisopaporn et al., 2015; Amekawa, 2010; Amekawa, 2013 ; Mergenthaler et al., 2009).

Sustainable cultivation practices pose new challenges because they require more complex technology and knowledge, involve trade-offs between agricultural productivity and sustainability, and have contrasting effects depending on the location of their application (Guerin, 2000; Läpple and Rensburg, 2011; Knowler and Bradshaw, 2007). Apart from that what is especially important is the carrying capacity of the biophysical environment in agriculture to determine sustainable cultivation (Buch Hansen, 2008). Good Agricultural Practices (GAP), promoted by $\mathrm{FAO}$, with the aim of improving quality agricultural practices, farmer income, and environmental health (Premier and Ledger, 2006). In other words the aim is to increase ecological, economic and social sustainability Akkaya et al. (2006), consumers have concerns about the control of food production and demand more information along the food chain. Good Agricultural Practice (GAP.) Then it is increasingly emphasized by the agreement of the ASEAN economic community in 2015 that requires all agricultural products from member countries to have the same quality standards.

GAP is one of the most important approaches developed to provide sustainability in agricultural production and

\footnotetext{
Corresponding author:

Email : oty.torus72@gmail.com

Phone : +62 852-6714-5836

Page: 129-139

p-ISSN 2301-9948 | e-ISSN 2407-6260
} 
Table 1

Area and Production of Pepper per Region in Indonesia in 2016

\begin{tabular}{|c|c|c|c|c|c|c|}
\hline \multirow[t]{2}{*}{ District } & \multicolumn{2}{|c|}{ Area (Hectare) } & \multirow{2}{*}{$\begin{array}{l}\text { Production } \\
\text { (Ton) }\end{array}$} & \multirow{2}{*}{$\begin{array}{c}\text { share } \\
(\%)\end{array}$} & \multirow{2}{*}{$\begin{array}{l}\text { Productivity } \\
(\mathrm{Kg} / \mathrm{Ha})\end{array}$} & \multirow{2}{*}{$\begin{array}{l}\text { Number of farmer } \\
\text { (household unit) }\end{array}$} \\
\hline & Total & $\begin{array}{c}\text { plants } \\
\text { produce }\end{array}$ & & & & \\
\hline Sumatera & 109909 & 63552 & 62703 & 31.12 & 987 & 157029 \\
\hline $\begin{array}{l}\text { Bangka } \\
\text { Belitung }\end{array}$ & 45701 & 22367 & 34909 & 39.09 & 1561 & 49427 \\
\hline Kalimantan & 18630 & 11906 & 14742 & 16.51 & 1238 & 31519 \\
\hline Sulawesi & 29141 & 16679 & 9918 & 11.11 & 595 & 54841 \\
\hline Java & 5742 & 3286 & 1831 & 2.05 & 557 & 36062 \\
\hline $\begin{array}{l}\text { Nusa } \\
\text { Tenggara, Bali }\end{array}$ & 518 & 294 & 101 & 0.11 & 344 & 1189 \\
\hline Maluku, Papua & 52 & 32 & 7 & 0.01 & 232 & 33 \\
\hline Indonesia & 163992 & 95749 & 89302 & & 933 & 280.673 \\
\hline
\end{tabular}

Source: Directorate General of Plantation 2017 (processed)

trade, and to ensure consumers the quality and safety of products and their origin (Gellynck, 2002). The application of GAP for pepper plants in the Bangka Belitung Islands Province is specifically aimed at making white pepper produced by farmers able to meet the quality standards required to be marketed internationally so that products that meet these quality standards are entitled to be labeled Muntok White Pepper. This is important because the production of white pepper produced by smallholder plantations shows a declining trend.

Pepper cultivation that is labor intensive and it is cultivated in the form of community plantations. In 2016, there were 280673 households working on pepper plantations in Indonesia, for white pepper in the Bangka Belitung Islands Province by 49427 families (Directorate General of Plantation 2017) so that it could be said that pepper plantations were able to absorb a large enough workforce for the community. The large need for labor in managing pepper farming makes pepper farming a business that is able to provide broad employment opportunities for the community. The area and pepper production in each region in Indonesia can be seen in Table 1.
In Table 1, it can be seen that the Bangka Belitung Islands Province is cultivating pepper plants produced as white pepper, with a production share of 39.09 percent of Indonesian pepper production. However, with this large production share, there are problems encountered in pepper farming in the Bangka Belitung Islands Province. This is indicated from the development of production and the total area of pepper in the Bangka Belitung Islands during 2007-2016 in general has increased, but specifically can be seen from the productivity that is still lower, compared to the potential productivity of pepper of 4 tons per hectare per year and lower from the productivity of pepper produced by Vietnam as the main competitor, amounting to 2.5-3.2 tons per hectare per year (IPC, 2016)

Many factors contribute to the decline in production. For example, change of land use, price volatility, climate change, plant diseases, lack of quality seeds, lack of available water supply and lack of knowledge of farmers about GAP, results in low productivity. Educating pepper farmers on this issue is very important to ensure farmers can obtain sustainable income from pepper farming. Maryadi, (2016), explains that the application of 
Good Agriculture Practices (GAP) with the use of certified superior seeds and the use of live climbing needs immediatelyto increase productivity at least $60 \%$ of the potential 2.5 tonnes/ha of dry white pepper. Based on this background, this study aims to analyze the factors that affecting the participation of white pepper farmers in Bangka Belitung Islands Province in the implementation of GAP and how GAP is implemeted by farmers.

\section{METHODOLOGY}

The research location was chosen purposively in accordance with the purpose of the study by selecting areas that have implemented Good Agricultural Practices in white pepper farming in 3 districts, namely South Bangka Regency, Central Bangka Regency and West Bangka Regency. The survey to pepper farmers was conducted in April to June 2019.

The sample in this study amounted to 224 respondents consisting of 142 farmers who applied GAP and 82 farmers who did not apply GAP. Farmers who do not apply GAP are pepper farmers in the same area as farmers who apply GAP. Sampling was carried out using a cluster sampling method.

Primary data were obtained directly from pepper farmers through interviews using a structured questionnaire prepared. The end result is a picture of the problem that is displayed through data tables and the variables are analyzed by statistical analysis. In addition, data or information obtained from the results of discussions and interviews with stakeholders of the Management Agency for Pepper Development and Marketing (BP3L) of the Province of Bangka Belitung Islands. Secondary data is also needed, obtained through written information and reports from relevant institutions or agencies such as the Central Statistics Agency (BPS), International Pepper Community (IPC), UN Comtrade, UNCTAD.

Factors affecting pepper farmers in implementing GAP were analyzed using the logit model. The logit model analyzes the response of binary scale independent variables that have values 1 and 0 .

$$
\begin{aligned}
\operatorname{Ln} \frac{P_{i}}{1-P_{i}}= & \beta_{0}+\beta_{1} x_{1}+\beta_{2} x_{2}+\beta_{3} x_{3}+\beta_{4} x_{4}+\beta_{5} x_{5}+ \\
& \beta_{6} x_{6}+\beta_{7} x_{7}+\beta_{8} x_{8}+\beta_{9} x_{9}
\end{aligned}
$$

Where $\mathbf{P}_{i}$ is farmer probability $i$ applying GAP, $0<P i<1, Y_{i}$ is GAP ( $y$ is 1 farmer who applies GAP, $\mathbf{y}$ is 0 farmer does not implement GAP), $\mathbf{X}_{1-9}$ is free variable, $\boldsymbol{\beta}_{0}$ is constant, $\boldsymbol{\beta}_{\boldsymbol{i}}$ is estimated parameter, $\mathbf{e}$ is natural number (2.7182).

In this study, the factors expected to influence the implementation of GAP by farmers consist of the age of farmers, formal education of farmers, length of experience of farming , number of family members, area of pepper harvest, distance to the market, activeness of following the GAP socializationand income outside of pepper farming. Processing logistic regression models uses Stata 14.

To see the magnitude of the change in the independent variable affecting changes in the dependent variable marginal effects are used. The marginal effect is obtained from the estimated coefficient with the following equation:

$\delta P / \delta X_{i j}=P i(1-P i) \beta j$, where $P i=\Lambda\left(x_{i} \beta\right)$

A goodness of fit test is performed to see how well a model can explain the relationship between the dependent variable and the independent variable. In logistic regression, the parameter seen for the goodness of fit test is Pseudo $R^{2}$, a mock R-square that is used because there is no equivalent that can replace R-square OLS in the logit model (Greene, 2000). Hosmer and Lemeshow (1989), proposed a goodness of fit test on the logit model with a statistical test of chi-square distribution that divides observations into several groups of the same size according to the predicted probability. Statistical tests with free degrees $M-k$ are:

$$
\chi^{2}=\sum_{j=1}^{M} \frac{\left(y_{j}-m_{j} p_{j}\right)^{2}}{m_{j} p_{j}\left(1-p_{j}\right)}
$$

Where $\mathbf{k}$ is number of independent variables, $\mathbf{M}$ is number of covariate patterns between observations $\mathbf{N}, \mathbf{j}$ is 
number of covariate patterns where $\mathbf{j}$ is 1 , $\ldots, \mathbf{M}, \mathbf{m}_{\mathrm{j}}$ is number of observations that have covariate pattern $\mathbf{j}, \mathbf{y}_{\mathbf{j}}$ is number of positive responses between observations with covariate patterns $\mathrm{jp}_{\mathrm{j}}$ is probability of a positive predicted outcome

Some steps in the logit regression model can answer the research objectives that are analyzing the factors that influence the application of technology as has been done by Basit (1995), Nuralam (2010) and Ejechi (2015).

To analyze the level of GAP application by white pepper farmers, using direct observation in the field and interviews, the analytical method used is descriptive analytic. Observation data on farmers' GAP implementation at the study site were compared with the Guidelines for GAP Implementation (IPC 2011). This method has also been applied by (Van Thanh and Yapwattanaphun, 2015). The level of implementation in each GAP component is calculated using the formula: \% implementation $=$ average implementation of sub-components in one component.

GAP implementation is divided into 4 score categories. GAP implementation is said to be low if the percentage of implementation is between $0 \%$ to $25 \%$; a little low if the percentage of $25.01 \%$ to $50.00 \%$; medium if the percentage is $50.01 \%-75.00 \%$; and implementation is categorized high if the percentage of implementation is $75.01 \%-100.00 \%$.

\section{RESULTS AND DISCUSSION \\ Principles and Application of Good Agricultural Practices white pepper} In principle, GAP practice is an effort to apply the rules of sustainability in crop cultivation systems (Tilman et al., 2002). The technology component in the white pepper GAP consists of land use that is free from contamination of hazardous chemical waste, management of growing media according to growing conditions by adding organic material, irrigation water management is ensured to be free from contamination of hazardous substances and pesticide residues and factory waste, use of seed varieties recommended, the use of live climbing poles, regular fertilization, pest control is naturally recommended, harvest and post-harvest pay attention to the criteria for ready-topick fruit (IPC, 2011).

The application of GAP depends on farmers' perceptions and participation as a decisive actor in managing their farming. For this reason, in the application of the white pepper GAP, the Regional Government together with the Pepper Development and Marketing Management Agency (BP3L) of the Bangka Belitung Islands Province provide guidance

Table 2

Performance of the Application of Technological Components of Good Agricultural Practices white Pepper at Research Location, in 2019

\begin{tabular}{|c|c|c|c|c|c|}
\hline \multirow{2}{*}{ No } & \multirow{2}{*}{ Technology component of GAP } & \multicolumn{3}{|c|}{ Application (\%) } & \multirow{2}{*}{ Criteria } \\
\hline & & Max & Min & Average & \\
\hline 1 & Land Selection & 100 & 25 & 73 & Medium \\
\hline 2 & Land management & 100 & 33 & 82 & High \\
\hline 3 & Water management & 100 & 50 & 95 & High \\
\hline 4 & Integrated crop management & 100 & 17 & 72 & Medium \\
\hline 5 & Pest control & 100 & 7 & 67 & Medium \\
\hline 6 & Harvest & 100 & 50 & 89 & High \\
\hline 7 & Post-harvest & 100 & 83 & 89 & High \\
\hline 8 & Quality standard & 100 & 50 & 85 & High \\
\hline
\end{tabular}

Source: Primary Data, 2019 
to farmers such as: providing capital assistance in the form of inputs, namely pepper seeds, urea fertilizer, TSP fertilizer and $\mathrm{KCL}$, there is technical guidance from the companion starting from the beginning of farming activities until post-harvest, there is a shelter as well as purchasing production results. The performance of applying white pepper GAP can be seen in Table 2.

Based on Table 2, it shows that the performance of the implementation of white pepper GAP by pepper farmers in Bangka Belitung Islands Province in 2019 for each component, on average ranged from 67 percent to 95 percent. Based on the interview results it was found that farmers who apply GAP believe that implementing GAP will increase farm productivity, produce agricultural products that are safe for consumption and have better quality. But the aspect of reduced pest attacks, farmers' safety guarantees, and certainty of the sustainability of farming is believed to have little effect. This incomplete level of understanding has caused the application of GAP to be not fully implemented.

In the land selection component, out of 142 farmers, only 119 people have elevations according to GAP guidelines, 91 suitable land slopes, 89 disease-free lands and 120 chemical-free lands.

The use of pepper seeds by farmers at this time is mostly in accordance with recommended varieties, which is applied by $72 \%$ of farmers or 103 people, but their productivity is still low at an average of 1.25 tons per hectare or only reaching 30 percent of optimal productivity. Under conditions of optimal growth conditions for productivity, healthy plants will be stable for 3 years or more, for Petaling I and II varieties are 4.5 tons per hectare, while productivity of Lampung Daun Kecil varieties have 3.8 tons per hectare (Research Institute for Medicinal and Aromatic Plants, 2011)

Pepper planting with recommended spacing rules has been done by $83 \%$ or 120 farmers, whereas fertilization and pruning are basically not in accordance with GAP guidelines. Farmers do not apply fertilizer recommendations because of the limited capital that is owned by farmers, so the dose of fertilizer used must be reduced.

Farmers rarely weed the weeds that grow around the crop. In this condition the amount of labor used is reduced, but the presence of weeds that are competing nutrients for plants distrub the crop's growth so that crop productivity decreases.

Controlling of stem rot disease (BPB) has not been carried out in accordance with GAP guidelines, the risk that can occur if the plant parts are not completely destroyed then it will be possible to spread to other plants. The costs to be incurred by farmers to deal with the spread of the next disease will be greater because farmers must also add manpower to clean up as soon as possible the infected pepper plants, so as not to spread throughout the farmers' land.

Pepper harvest time has been carried out in accordance with GAP guidelines, that is, after 8-9 months; the exact harvest time determines the quality of pepper to be processed for the next stage.

Pepper processing after harvest is carried out by farmers in the traditional way, relying on a pool around the village for soaking the pepper for 1 to 2 weeks. If the farmer soaks the pepper by making a washing tank and flowing with running water, the pepper results are cleaner and save time of soaking. Pepper which has a moisture content of less than $12 \%$, has a clean white color and is not mixed with dirt will be purchased by collectors at a higher price.

\section{Household and Farm Characteristics}

Pepper farming households have different household and farming characteristics. The different characteristics affect farmers' decision to implement GAP. In general, farm households that apply GAP have an average younger age than non-GAP farmers. Even so, the average age of the head of a farmer's family is still classified as a productive age. A comparison of the 
Table 3

Comparison of Farm Household Characteristics Applying GAP and Non-applying GAP

\begin{tabular}{lccc}
\hline \multirow{2}{*}{ Variable } & \multicolumn{2}{c}{ Mean } & \multirow{2}{*}{ p-value } \\
\cline { 2 - 3 } & GAP & Non GAP & \\
\hline Age of farmer & 45.3 & 47.8 & 0.0864 \\
Farmer's formal education & $9.4^{*}$ & $8.4^{*}$ & 0.0140 \\
Farming Experience & $24.9^{*}$ & $28.2^{*}$ & 0.0246 \\
Number of family members & $3.3^{*}$ & $2.9^{*}$ & 0.0149 \\
Number of man-day of family labor & $48.3^{*}$ & $17.1^{*}$ & 0.0000 \\
Number of man-dayof hired labor & 28.5 & 32.7 & 0.3892 \\
Pepper harvest area & 0.96 & 0.87 & 0.2488 \\
Number of plants & 1511 & 1286 & 0.0610 \\
Market Distance & 12.3 & 12.2 & 0.9471 \\
Pepper farm income & $42500000^{*}$ & $25000000^{*}$ & 0.0001 \\
Off-farm income & 31200000 & 29000000 & 0.8479 \\
\hline
\end{tabular}

Note:* the difference between GAP and non-GAP farmers is significant at $p=0.05$

Source: Primary Data, 2019

characteristics of farm households that apply GAP and those that do not apply GAP is presented in Table 3.

The level of education of family heads of farmers who apply GAP has a higher average value than farmers who do not apply GAP. The average length of education of farmers who apply GAP is 9.4 years or equivalent to completing junior high school (SMP) education, whereas for farmers who do not apply GAP the average education of family heads is 8.4 years or equivalent to not completing junior high school education. Furthermore, based on the number of household members, farmers who apply GAP and who do not apply GAP have the same average household members as many as 3 people. This figure implies that, on average, pepper farmer households, both farmers who apply GAP and those who do not apply GAP, bear 3 household members so that they are included in the small family category.

Pepper land tenure by farmers who apply GAP is not significantly different from farmers who do not apply GAP. Farmers who apply GAP control land by an average of 0.96 ha, whereas farmers who do not apply the GAP of 0.87 ha. Data from the field shows that all pepper farms are farmers' land. This indicates that pepper farming has been inherited from previous generations; this is a local wisdom to maintain pepper farming as an annual crop which is also an investment commodity for pepper farmer households so that farmers have the discretion to manage resources if they own their land.

White pepper harvested from pepper orchards managed by farmers must go through several stages of post-harvest processing to obtain dried pepper that is ready to be sold to collectors. The distance of the farmer household from the traders and the market influences the farmer's decision to sell the harvest. The average distance for farmers who apply GAP and farmers who don't apply GAP is not too different. This is because the sampling of farmers who do not apply GAP as the control variable in this study is based on the location closest to farmers who apply GAP.

The average household income of farmers who apply GAP obtained from pepper farming is higher than farmers who do not apply GAP. Based on the calculation, the contribution of pepper farming to the 
household income of farmers reached 57.6 percent, while the farmers who did not apply GAP pepper farming contributed only 46.2 percent. From the results of observations in the field that the higher income is due to the higher productivity and selling prices received by farmers who apply GAP.

\section{Factors that Influence Farmers in Ap-} plying white Pepper GAP

The logit model is used to estimate the factors that influence farmers' participation in apply GAP. The results of testing the goodness of the model using the HosmerLemeslow's test obtained the probability value of the chi ${ }^{2}$ statistical test that is equal to 0.6560 , greater than $\alpha=0.05$. it means that the model is fit for use in predictions. The ability of the model to predict correctly was 68.51 percent. The results of estimation of factors that influence farmers in implementing GAP are presented in Table 4.

The parameter testing is carried out simultaneously and partially. Simultaneous testing uses the likelihood ratio test. The test results obtained by the LR chi2 value of 47.66 with Prob> chi2 is 0.0000 . This shows that the independent variables in the model simultaneously influence the participation of farmers applying GAP. Partial test was carried out using the Wald test. Partial test results indicate that the participation of farmers in implementing GAP is influenced by the age of farmers, formal education of farmers, experience of farming, the number of family members, the area of pepper harvest area, and the activity to participate in GAP socialization.

Farmer age has a positive sign and has a significant effect with $\mathrm{p}$-value $<\alpha=$ 0.05 . It means that as farmers grow older the probability of farmers to apply GAP to their farming will increase. The marginal effect value of the age of the farmer is 0.0386 . It means if the average age of farmers increases by 1 year, the probability of farmers to implement GAP increases by 3.86 percent. According to data in the field, it is found that farmers who apply GAP are dominated by age 41-60 years while those aged less than 30 years are only 7 percent. These results is the same as those of Rajendran et al. (2016), and studied by scientists seeking to understand their response to these alternative agricultural approaches. This paper reviews and synthesizes recent research in this area. It identifies key explanatory factors, which frequently lead to the adoption of bundled SAPs. Vote count analysis reveals that variables implying economic motivation and facilitation regularly explain farmers' behaviour. In addition, a new finding emerged, in which factors inferring higher learning and superior management capacity provided further indicators to adoption. In particular, the training that provided by non-governmental organizations and rural institutions complements change agents (i.e. public extension services, but it is different from the result of Terano et al. (2015), as well as increasing chronic and acute health problems for farmers who mishandle or not follow proper procedures in applying the chemicals. Sustainable agriculture is thus becoming an important concept in alerting the management about controversial agricultural practices. The objective of this study is to investigate the paddy farmer's intention to practices sustainable agriculture and to determine the significant factors that could be used as predictors in having intention to practice sustainable agriculture. Thus, in order to disseminate sustainable agriculture, it is absolutely necessary to comprehend the farmer's intention to apply sustainable farming practices based on Good Agricultural Practices (GAP).

Farmer formal education has a positive sign and has a significant effect with $p$-value $<\alpha=0.10$. That means the higher level of education that farmers have, the probability of farmers to apply GAP to their farming will increase. The marginal effect value of the formal education of farmers is obtained by 0.0203 , it means that if the average level of formal education of farmers increases by 1 year, the probability of farmers to apply GAP increases by 2.0 percent. These results are the same as 
those ofSrisopaporn et al. (2015), the higher the education level of farmers will lead to an increase in the level of farmer participation in the implementation of GAP.

The number of family members has a positive sign and has a significant effect on the $p$-value $<\alpha=0.05$, it means that the greater the number of family members of the farmer, the probability of farmer participation to implement GAP willincrease. The marginal effect value of the number of family members obtained by 0.0734 , it means that if the average number of farm family members increases by 1 person, the probability of farmers to implement GAP will increase by 7.34 percent. The facts on the ground are found that pepper farmers have more family members and that will facilitate the availability of labor in plant maintenance activities such as fertilizing, also in harvesting and post-harvesting activities. Whereas farmers, whose family members are, few are forced to seek wage labor. The number of family members is also a significant factor in implementing sustainable certification in green tea in Vietnam (Tran and Goto, 2019).

Farming experience owned by farmers is illustrated by counting the number of years since farmers started pepper farming. The negative influence of the experience of pepper farming shows that more experienced pepper farmers tend to choose to survive with traditional cultivation techniques because it is more practical than GAP which takes more time and energy such as the use of dead climbing poles that are more practical than environmentally friendly climbing poles. The results of research on different commodities carried out by Thapa and Rattanasuteerakul (2011), who support this statement.

The harvested area has a positive sign and has a significant effect on $p$-value $<\alpha=0.05$, it means that the greater the pepper farms managed by farmers, the probability of farmers participating in implementing GAP will increase. The marginal effect value of the farmers' land area is obtained by 0.1508 and it means if the average farmer's land increases by 1 ha, the probability of farmers participating in implementing GAP increases by 15 percent. This shows that farmers will feel they can have a real influence on good aspects of agriculture if they have sufficient land area. Conversely, when they feel that the land is not economically sufficient and the ecological impact caused is considered to be small, the principles of GAP are ignored. These results are the same as the results of Van Thanh and Yapwattanaphun (2015), research on farmers in a province in Thailand on the application of sustainable agriculture, which explains that there are only $35 \%$ who want to adopt the principles of good and environmentally friendly agriculture due to the land owned by small farmers. In addition it seems that economies of scale also play a major role in determining farmers to implement GAP (Mausch et al., 2006). As a comparison that land area factors can also negatively affect the application of technology in farming, this is evidenced by Yaron et al. (1992), which concludes that to increase production farmers prefer to use inputs other than land intensively rather than increasing the area of planting farming.

While the positive effect of activeness of farmers in GAP socialization is shown by the marginal effect value of 1,642 , which means that the greater the number of farmers attending or participating in GAP socialization activities, the probability of farmers to implement GAP will increase 164 percent. Research by Yaron et al. (1992), Thapa and Rattanasuteerakul, (2011) supports this statement.

Overall the results of this study can be compared with the results of research on the application of GAP in Thailand, it turns out that in Thailand the adoption of GAP is managed entirely by the government, from setting standards for training, auditing, and issuing certificates (Sarsud, 2007). This reality is far different from what is found in the Bangka Belitung Islands Province, that the application of GAP by farmers is generally done independently, there is counseling and training on the application 
of GAP attended and participated by a small number of farmers so that farmers do not get too much assistance that they really need in its implementation. In addition, research in China conducted by Luo et al. (2016), shows that many factors can influence farmers' decisions to accept and adopt environmentally friendly farming practices, but the cost factor is the most important, followed by the ease of farmers to observe and risk factors. Whereas in Turkey, it turns out that factors that can hinder or limit the application of GAP are fragmented area structure, small land size, lack of registration by farmers and limited farmer unions Akkaya et al. (2006), consumers have concerns about the control of food production and demand more information along the food chain. Good Agricultural Practice (GAP).

Based on this description, the application of GAP depends on various factors that exist at the location of the application but it is important to overcome various obstacles with the right effort according to the conditions that exist in the farm. Research conducted Pongvinyoo, et al. (2014), concluded that to reduce barriers to the adoption of GAP by farmers, collaboration between the government and the private sector is crucial in the adaptation of standards.

\section{CONCLUSIONS}

Based on the results of the study it can be concluded that the variables that positively influence farmers in implementing GAP are the age of farmers, formal education of farmers, the number of family members, the area of pepper harvested area and the activeness of farmers in attending GAP socialization. While the variables that negatively affect the experience or the length of time pepper farming has been done by farmers. The implementation of white pepper GAP by pepper farmers in Bangka Belitung Islands Province in 2019 for each component, on average ranged from 67 percent to 95 percent. Increasing the participation of white pepper farmers in Bangka Belitung Province in implementing GAP requires joint efforts from the parties. In connection with the problem of increasing production costs in this white pepper farming, the government needs to encourage the private sector to act as guarantor for financing and marketing of white pepper so that the price of pepper becomes more fair and profitable. The private sector needs to develop a cooperation model that is able to ensure that farmers receive benefits from the implementation of the GAP. Research on the factors that influence farmers 'participation in implementing GAP can add other variables such as incentive variables received by farmers, farmers' level of trust, and farmer's motivation.

\section{REFERENCES}

Akkaya, F., Yalcin, R. and Ozkan, B. (2006). Good Agricultural Practices (GAP) and its implementation in Turkey. Acta Horticulturae, 699, 47-52. 10.17660/ActaHortic.2006.699.3.

Amekawa, Y. (2010). Rethinking Sustainable Agriculture in Thailand: A Governance Perspective. Journal of Sustainable Agriculture, 34(4), 389416. 10.1080/10440041003680254.

Amekawa, Y. (2013). Can a Public GAP Approach Ensure Safety and Fairness? A Comparative Study of Q-GAP in Thailand. Journal of Peasant Studies, 40(1), 189-217. 10.1080/03066150.2012.746958.

Buch-hansen, M. (2008). Is Sustainable Agriculture in Thailand Feasible?. Journal of Sustainable Agriculture, 18(2), 37-41. 10.1300/J064v18n02.

Gellynck, Xavier. (2002). Changing Environment and Competitiveness in the Food Industry Veranderende Omgeving en Competitiviteit in de Voedingsindustrie. Thesis. Faculteit Economie en Bedrijfskunde Universiteit Gent. 
Guerin, T. F. (2000). Overcoming the Constraints to the Adoption of Sustainable Land Management Practices in Australia. Technological Forecasting and Social Change, 65(2), 205-237. 10.1016/S00401625(99)00090-6.

Hosmer, D. W. and Lemeshow, S. (2004). Applied Logistic Regression Second Edition. WILEY. $10.1002 / 0471722146$.

IPC. (2016). Pepper Statistical Year Book 2006-2015. Jakarta: INTERNATIONAL PEPPER COMMUNITY.

Knowler, D. and Bradshaw, B. (2007). Farmers' Adoption of Conservation Agriculture: A Review and Synthesis of Recent Research. Food Policy, 32(1), 25-48. 10.1016/j. foodpol.2006.01.003.

Läpple, D. and Rensburg, T. Van (2011). Adoption of Organic Farming: Are there Differences Between Early and Late Adoption?. Ecological Economics, 70(7), 1406-1414. 10.1016/j.ecolecon.2011.03.002.

Luo, L., Qin, L., Wang, Y., \& Wang, Q. (2016). Environmentally-friendly Agricultural Practices and their Acceptance by Smallholder Farmers in China - A Case Study in Xinxiang County, Henan Province. Science of the total environment, 571, 737-43. 10.1016/j.scitotenv.2016.07.045.

Maryadi. (2016). Analisis Usaha Tani Lada dan Arahan Pengembangannya Di Kabupaten Bangka Tengah. Sekolah Pascasarjana Institut Pertanian Bogor. http://repository.ipb.ac.id/ jspui/bitstream/123456789/80506/1/ 2016mar.pdf.
Mergenthaler, M., Weinberger, K. and Qaim, M. (2009). Consumer Valuation of Food Quality and Food Safety Attributes in Vietnam. Review of Agricultural Economics, $31(2), \quad 266-283 . \quad 10.1111 / \mathrm{j} .1467-$ 9353.2009.01437.x.

Pongvinyoo, P., Yamao, M. and Hosono, K. (2014). Factors Affecting the Implementation of Good Agricultural Practices (GAP) among Coffee Farmers in Chumphon Province, Thailand. American Journal of Rural Development, 2(2), 34-39. 10.12691/ajrd-2-2-3.

Premier, R. and Ledger, S. (2006). Good Agricultural Practices in Australia and Southeast Asia', 16(December), 2-5.

Rajendran, N., Tey, Y. S., Brindal, M., Ahmad Sidique, S. F., Shamsudin, M. N., Radam, A., \& Abdul Hadi, A. H. I. (2016). Factors Influencing the Adoption of Bundled Sustainable Agricultural Practices: A Systematic Literature Review. International Food Research Journal, 23(5), 22712279. http://www.ifrj.upm.edu.my.

Research Institute for Medicinal and Aromatic Plants. (2011). Good Agricultural Practices for Pepper (Pedoman Budidaya Lada Yang Baik) Versi Indonesia disusun untuk petani. Jakarta. INTERNATIONAL PEPPER COMMUNITY.

Srisopaporn, S., Jourdain, D., Perret, S. R., Shivakoti, G. P. (2015). Adoption and Continued Participation in a Public Good Agricultural Practices program: The Case of Rice Farmers in the Central Plains of Thailand. Technological Forecasting and Social Change, 96, 242-253. 10.1016/j. techfore.2015.03.016. 
Terano, R., Mohamed, Z., Shamsudin, M. N. (2015). Factors Influencing Intention to Adopt Sustainable Agriculture Practices Among Paddy Farmers in Kada, Malaysia. Asian Journal of Agricultural Research, 9(5), 268275. 10.3923/ajar.2015.268.275.

Van Thanh, N. and Yapwattanaphun, C. (2015). Banana Farmers' Adoption of Sustainable Agriculture Practices in the Vietnam Uplands: The Case of Quang Tri Province. Agriculture and Agricultural Science Procedia, 5, 6774. 10.1016/j.aaspro.2015.08.010.

Thapa, G. B. and Rattanasuteerakul, K. (2011). Adoption and Extent of Organic Vegetable Farming in Mahasarakham Province, Thailand', Applied Geography. 31(1), 201-209. 10.1016/j.apgeog.2010.04.004.
Tilman, D., Cassman, K. G., Matson, P. A., Naylor, R., Polasky, S. (2002). Agricultural Sustainability and Intensive Production Practices. Nature, 418(6898), 671-677. 10.1038/ nature01014.

Tran, D. and Goto, D. (2019). Impacts of Sustainability Certification on Farm Income: Evidence from Small-Scale Specialty Green Tea Farmers in Vietnam. Food Policy, 83, 70-82. 10.1016/j.foodpol.2018.11.006.

Yaron, D., Dinar, A. and Voet, H. (1992). Innovations on Family Farms: The Nazareth Region in Israel. American Journal of Agricultural Economics, 74(2), 361. 10.2307/1242490. 